\section{FICTION BOOK REVIEW}

\section{The Marriage Plot}

Jeffrey Eugenides. London, UK: Fourth Estate, 2011. ISBN-13: 978-0-007-44130-3. Price: $£ 8.99$.

Pages: 416 (paperback)

The Marriage Plot is a richly woven book set in the early 1980s. Its story begins at the graduation weekend of an Ivy League university, with the three principal characters in a state of distress and uncertainty amidst the end of studies festivities.

It is 1982, and punk rock and feminism are still strong amongst female students. This is the year that Columbia University admits its first female undergraduates. Madeleine, however, has a passion for the past and for romantic 19th century literature and a liking for orderly things. Up to now Madeleine's life has been sheltered and privileged, in stark contrast to that of the man whose life she now wants to share as they prepare to leave campus. Leonard is considered an exceptional biology student. He has a mercurial mind, a Casanova reputation and a dark side with a mental health problem that he tries to keep hidden. Madeleine has an overwhelming sexual attraction for Leonard that is disturbing her sense of reason to the point of vulnerability. Concerned friends try to sway Madeleine from continuing her relationship with Leonard. One of these friends is Mitchell, a fellow student, who is tormented by his unfulfilled love for Madeleine, unable to push past their platonic situation and reveal this to her.

On the morning of their graduation ceremony Madeleine discovers that Leonard is bipolar, and finding him in an acute manic state and fuelled with the belief that she can save him, she skips the graduation ceremony and enters into a relationship where she will find herself colluding with Leonard's illness and becoming co-dependent.

The title of The Marriage Plot suggests some romance and there are indeed warm heart-rending moments in the book alongside the inexperienced and experimental sexual encounters that are part of the undergraduate curriculum of selfdiscovery. But what I really found poignant in Jeffrey Eugenides' book is his excellent description of the descent into depression and despair of someone with bipolar disorder and the effects of the unpredictability and fear that this illness has on those close to them.

Whilst his sexual prowess appears to be one of Leonard's greatest attractions, hyper-sexuality is considered to be a primary symptom in bipolar disorder, but perhaps the one less talked about. Had Madeleine met Leonard at a different stage in his bipolar cycle things might have been quite different.

All in all I enjoyed The Marriage Plot. It is a hugely descriptive book that provides the reader with an attention to detail that enables them to see and feel their way through its surroundings. I welcomed the overlapping style where each section is dovetailed with the previous one, thereby moving each of its characters forward. A good read.

Reviewed by Lesley Ashdown-Barr

Research Nurse, Centre for Cancer Prevention, Wolfson Institute of Preventive Medicine, Queen Mary, University of London, London, UK

J Fam Plan Reprod Health Care 2012;38:251. doi:10.1136/jprhc-2012-100461 